\title{
Cultures pérennes : prendre en compte les dynamiques du dedans
}

Oléagineux, Corps Gras, Lipides. Volume 8, Numéro 6, 557, Novembre - Décembre 2001, Editorial

Auteur(s) : Jean-Claude ICART

\section{ARTICLE}

Enjeu majeur pour les pays en développement (dont certains parmi les plus pauvres), les cultures pérennes partagent un certain nombre de caractéristiques : investissements lourds pris pour une longue durée, problèmes de la disponibilité en terre pour les replantations, confrontation nouvelle à des contraintes de sécurité sanitaire, aux risques environnementaux, etc. Mais une de ces données parmi les plus prégnantes tient au fait, souvent souligné, que ces cultures sont devenues tributaires au niveau national d'un environnement macroéconomique rendu conforme aux prescriptions des agences (FMI, Banque mondiale) et autres bailleurs de fonds internationaux.

Les politiques d'ajustement structurel (PAS), les réformes des marchés, les mesures de déréglementation et de privatisation (de minoration du rôle de l'État) cherchant à promouvoir de nouveaux modes de gestion - conditions d'une croissance soutenue - ont, de fait, profondément modifié l'environnement institutionnel, technique et économique des producteurs (le plus souvent villageois) ${ }^{1}$.

Les résultats faibles, parfois négatifs ${ }^{2}$, enregistrés, conduisent ainsi à s'interroger non sur la pertinence des réformes mises en place - objet d'un large consensus chez les économistes - mais sur les conséquences (faiblement analysées) effectives, sociales et économiques, de ce nouveau partage des rôles entre l'État et les marchés, comme il conduit à tenter de cerner la nature complexe des processus en cours au sein des systèmes ruraux des pays du Sud.

En cette période de crise du " développement », de crise de la " réflexion sur le développement » (et de crise de "l'aide au développement »), cet éclairage microéconomique des " dynamiques du dedans ${ }^{3}$, et de leur logique à déterminants multiples, se révèle constituer le point de départ et la base obligée de toute proposition d'action en termes de politique économique et de recherche.

Le fait que la conférence de Yamoussoukro de novembre dernier, réunissant des chercheurs rarement présents ensemble dans les colloques, ait permis d'avancer dans l'établissement et l'expression de ces analyses, en souligne l'importance et l'intérêt.

Le développement économique, comme le rappelle la résolution de la conférence, suppose que l'État assure aux acteurs un horizon de long terme. II implique également la prise en compte des dynamiques endogènes des micro-entreprises et des petites activités de base.

Multidimensionnelle par nature, l'activité agricole se déploie sur des réalités culturelles, historiques, territoriales, techniques, économiques, juridiques, environnementales, traditionnellement solidaires au Sud. Comment un processus de développement durable pourrait-il être formulé sans s'appuyer sur ces ancrages?

Il y a là, en particulier pour la recherche, un enjeu stimulant et un impressionnant défi.

Jean-Claude Icart 
Notes :

${ }^{1}$ Voir « Afrique : présent et avenir des cultures pérennes », Dossier OCL $2000(7,2)$ et " Aspects des filières semencières Nord/Sud », Dossier $\operatorname{OCL} 2001(8,5)$.

${ }^{2}$ Globalement, la part de l'Afrique dans le commerce mondial a été réduite de moitié entre 1970 et 2000.

${ }^{3}$ Philippe Hugon, Économie de l'Afrique, Paris : La Découverte, 2001. 